\title{
Concentration and reactivity of the sulphydryl group population on the membrane of intact erythrocytes in patients with rheumatoid arthritis
}

\author{
C Chilles, M Mulheron, F M McCrae, J Reglinksi, W E Smith, M Brzeski, R D Sturrock
}

\begin{abstract}
The sulphydryl population on erythrocyte membrane is shown to vary as a function of the nutritional status of the cell. When an assay based on reaction with Ellman's reagent and controlled conditions were used the mean values (SEM) for the sulphydryl population on the membranes of normal erythrocytes incubated overnight in the presence and absence of glucose were found to be $3.29(0.27)$ and $2.56(0.25)$ million sulphydryl functions per cell respectively. Under identical conditions rheumatoid erythrocytes incubated in the presence and absence of glucose were found to have a significantly lower sulphydryl population-1.54 $(0.08)$ and $1.15(0.08)$ million respectively.

The predominant concentrations of sulphydryl groups on the membrane are found at sites on the transmembrane proteins and, in particular, on the hexose transport protein. By influencing the nutritional status of the cells significant differences in activity between the normal and diseased state have been identified and these may have a role in the aetiology of rheumatoid arthritis by altering the response of cells to oxidative stress.
\end{abstract}

Plasma sulphydryl group concentrations are known to be low in rheumatoid arthritis and to be raised to some extent during treatment with penicillamine ${ }^{1}$ and gold compounds. ${ }^{2}$ The sulphydryl group concentration can be subdivided into fast or reactive thiol and slow or comparatively unreactive thiol. It is mainly the fast thiol which is affected during treatment. ${ }^{3}$ Both gold compounds and penicillamine would be expected to react with the available thiols in vivo. During treatment with these compounds, however, alteration in the plasma thiol concentration tends to be slow and follows signs of clinical improvement rather than rises in plasma gold or penicillamine concentrations. Thus the change is likely to follow amelioration of disease activity rather than cause it.

The intracellular thiol concentration (mainly glutathione) increases within the first few weeks of treatment in patients who subsequently improve. ${ }^{4}$ We have noted that during treatment with sodium aurothiomalate most of the gold present in the red cell is in the membrane rather than the cytosol, particularly in non-smokers, ${ }^{56}$ and that in the in vitro experiments with penicillamine some penicillamine crossed the membrane but much of it was absorbed or reacted causing changes in cellular function. 78

Likely sites for these therapeutic agents to react on the membrane are the available exofacial thiols, and in this preliminary study we have investigated the question of how such groups are altered in rheumatoid arthritis. This initial study was carried out with patients who were not being treated with disease modifying agents as these drugs may further affect the thiol status of the cell membrane. ${ }^{5-7}$

\section{Materials and methods}

All reagents used in this study were commercially obtained unless otherwise stated. Whole blood was collected in heparinised anticoagulant tubes from 10 healthy normal volunteers and 10 patients with classical or definite rheumatoid arthritis as defined by the American Rheumatism Association criteria. The latter were not receiving any prescribed second line or cytotoxic drugs.

Samples were centrifuged at $3000 \mathrm{rpm}$ for 10 minutes and the supernatant fluid and the buffy white coat removed by suction. The resulting cells were washed three times in $0.125 \mathrm{M} \mathrm{Na}_{2} \mathrm{HPO}_{4}$; $0.15 \mathrm{M} \mathrm{NaCl}$ buffer (adjusted to pH 7.4 with concentrated hydrochloric acid). The samples were divided into two roughly equal volumes and stored in buffer and buffer/glucose ( $5 \mathrm{mM})$ overnight at $4^{\circ} \mathrm{C}$ in sealed containers (about 16 hours) to produce glucose depleted and activated cells. After this the cells were washed with their respective media: phosphate/saline, with or without 5 $\mathrm{mM}$ glucose. The supernatants were carefully checked for lysis by eye and by spectrophotometry $(\lambda=541 \mathrm{~nm})$. Lysed samples were discarded.

The number of cells in a given volume of pellet were counted, and $0.5 \mathrm{ml}$ was transferred to a sterile container with $8.5 \mathrm{ml}$ of the respective buffers and $1.0 \mathrm{ml}$ of $10^{-3} \mathrm{M}$ Ellman's solution. The container was gently mixed and allowed to react for 30 minutes. The suspensions were then centrifuged ( $3000 \mathrm{rpm}$ for 10 minutes), the supernatant removed, and the visible spectrum $(600$ $350 \mathrm{~nm}$ ) recorded. The concentration of Ellman's anion was calculated using Beer's law (molar absorbance $\varepsilon_{\max }$ for $\mathrm{ES}^{-}=13600 \mathrm{~cm}^{2} / \mathrm{mol}, 412$ $\mathrm{nm}^{*}$ and used in the equation below to give the total number of thiols present on the surface of the membrane.

Total number of thiols present on the erythrocyte membrane

[ES $\left.{ }^{-}\right] \times$volume $\times$Avogadro's No where $\left[\mathrm{ES}^{-}\right]$is the concentration of Ellman's anion in solution calculated using Beer's law.

The change in sulphydryl group concentration on the membranes of depleted cells as a result of glucose addition is monitored by adding sugar to a depleted erythrocyte suspension and then sampling at specific time intervals before addition of Ellman's reagent.

\section{Results and Discussion}

Ellman's reagent (ESSE) is an accepted method of assaying biological fluids ${ }^{10-12}$ and membranes ${ }^{13} 1_{4}$ 
for the sulphydryl group (equations 1 and 2). Recent studies have shown that it can also be used with intact erythrocytes as a probe of exofacial membrane function and activity, ${ }^{15}$ provided that lysis is kept to a minimum by careful control of the experimental conditions, including the ESSE concentration. The reaction is,

$$
\mathrm{ESSE}+\mathrm{RSH} \longrightarrow \mathrm{ES}^{-}+\mathrm{RSSE}+\mathrm{H}^{+}
$$

$\mathrm{ESSE}+$ Membrane $-\mathrm{SH} \longrightarrow \mathrm{ES}+$ Membrane $-\mathrm{SSE}+\mathrm{H}^{*}$

Ellman's reagent has some definite advantages for the assessment of thiol status on cell membrane. It cannot pass through the membrane and is specific for the sulphydryl function and, furthermore, requires no preparation procedures using radioactive materials. Thus it is possible to estimate the number of thiols and their activity on the cell in the intact state. At high concentrations or with prolonged incubation lysis can be a major problem, however. This may be controlled in two ways. The concentration of Ellman's reagent in contact with the cells can be kept low ( $\leqslant 1 \mathrm{mmol} / \mathrm{l})$. It is then necessary to use a fairly large volume of Ellman's solution to ensure that sufficient amounts are present to saturate the sulphydryl populations.

The contact time of these solutions must also be controlled. The reaction of a small thiol containing species with Ellman's reagent in solution (equation 1 ) is rapid with a $t_{12}$ of less than five minutes. The reaction of a surface based moiety with a solution phase species can take an order of magnitude longer to react. Lysis can be estimated in the visible spectra by the presence of the haemoglobin band at $541 \mathrm{~nm}$ and is usually detectable after about three hours. To prevent interference from this source and from the regeneration of the surface thiols by the cell the shorter time period of 30 minutes was used. The Ellman's reagent solution employed was $10^{-3} \mathrm{M}$ as this was found to provide the most efficient anion generation over the allowed time period.

The sulphydryl populations on the red cell membrane are a direct reflection of the concentration and status of certain proteins in the membrane (fig 1). Thus although a rough value of $10^{6}$ sulphydryl groups per cell is to be expected ${ }^{16-19}$ (table 1), the actual value will vary depending on
Table 1 Number and distribution of sulphydryl groups on the exofacial surface of erythrocyte membrane $e^{16-79}$ assayed by radiolabelling techniques*

\begin{tabular}{|c|c|c|c|c|}
\hline Band & $\begin{array}{l}\text { Molecular } \\
\text { weight }\end{array}$ & $\begin{array}{l}\text { No of } \\
\text { thiols/cell }\end{array}$ & $\%$ & Function \\
\hline $\begin{array}{l}3 \\
4 \cdot 5 \\
6 \\
7\end{array}$ & $\begin{array}{l}89000 \\
40000-70000 \\
36000 \\
32000 / 34000\end{array}$ & $\begin{array}{l}1.3 \times 10^{5} \\
6.2 \times 10^{5} \\
1.1 \times 10^{5} \\
1.3 \times 10^{5}\end{array}$ & $\begin{array}{l}13 \\
63 \\
11 \\
13\end{array}$ & $\begin{array}{l}\text { Anion transport } \\
\text { Hexose transport } \\
\text { Unknown } \\
\text { Antigens (two proteins) }\end{array}$ \\
\hline
\end{tabular}

*The exofacial surface of the erythrocyte membrane is defined by the degree of penetration of the $N$-ethylmaleimide radiolabe used to obtain these data. Depending on the permeability of Ellman's reagent the number of thiols available for binding especially in the trane by this table.

the number of protein copies per erythrocyte sample.

It is now becoming apparent that the sulphydryl moiety is important to protein function. For example, the $\mathrm{Rh}_{\text {null }}$ antigen proteins ${ }^{20}$ are known to have lost the sulphydryl groups common to other rhesus blood groups. In addition, changes in the exofacial thiol population of the hexose transport protein during glucose binding and transport have been reported. ${ }^{21-24}$

With Ellman's reagent as a chemical probe of the sulphydryl population, we found values of between 1.7 and 4.8 million sulphydryl groups/cell for erythrocytes from normal healthy volunteers (fig 2). The mean values in millions of sulphydryl groups were as follows: normal cells + glucose $3 \cdot 29$ (SEM 0.27); normal cells-glucose $2.56(0.25)$; rheumatoid cells +glucose $1.54 \quad(0.08) ;$ and rheumatoid cells-glucose $1 \cdot 15(0.08)$.

The difference between the activated normal cells and the activated rheumatoid cells was analysed with the Mann-Whitney $U$ test. A significant $(p<0.01)$ difference was found between these two groups. A significant $(p<0.01)$ difference was also found, by the same method, between depleted normal cells and depleted rheumatoid cells.

The difference between the activated and deactivated normal cells was analysed with the Wilcoxon matched pairs signed rank test, and was found to be significant $(p<0.01)$. When this test was applied to the two rheumatoid populations

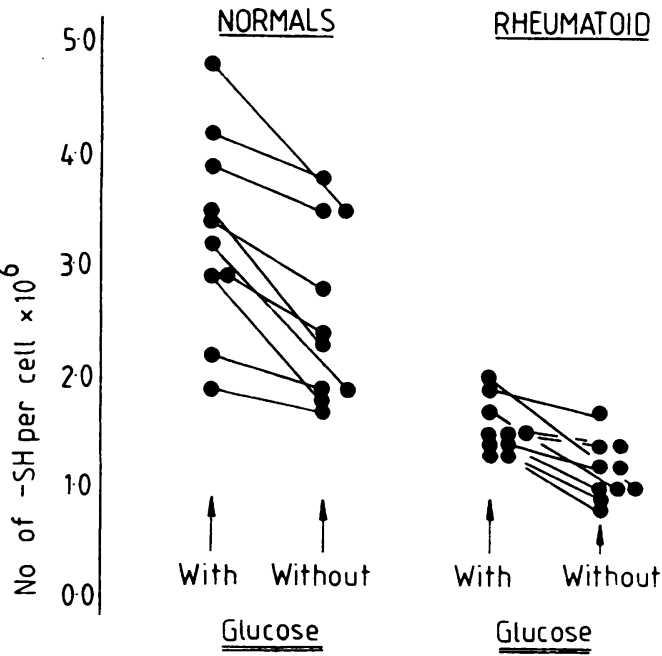

Figure 2 Sulphydryl group populations for erythrocytes from 10 healthy normal volunteers and from 10 patients with rheumatoid arthritis in the presence and absence of glucose, given as sulphydryl functions per cell. Sample pairs are linked by solid lines.
Figure 1 A schematic diagram of the enythrocyte membrane. The spatially isolated proteins correspond to the band 6 and 7 proteins as defined by sodium dodecyl sulphate gel electrophoresis. 
(depleted and activated) a significant $(p<0.01)$ difference was also found.

The values above are somewhat larger than the number quoted above in table 1 , largely because of the differences between the methods of assessment. Radiochemical counting of electrophoretic bands follows extensive separation and does not include minor components. The sulphydryl groups on the proteins are also susceptible to oxidation during preparation and electrophoretic separation. The permeabilities of $N$-ethylmaleimide used in sodium dodecyl sulphate gel electrophoresis assays and Ellman's reagent used here will be different, with the latter believed to be more permeant. Table 2 shows the overall distribution of sulphydryl groups throughout the entire red cell membrane. ${ }^{17} \mathrm{~A}$ large percentage $(41 \%)$ of the thiol functions of the membrane are found in the interior by virtue of contributions by the two transmembrane transport proteins (table 1). Notice that a minor increase in the permeability of the thiol probe molecule will tap some of these deeper seated thiols and would be expected to produce a significant increase in the thiol assay and subsequently alter the percentage distribution of the exofacial sulphydryl population shown in fig 1 . Thus the Ellman's assay used here might be expected to provide a more accurate assessment of the total exofacial thiol, and the difference between the methods is as would be expected considering that the definition of the term 'exofacial sulphydryl group' depends on the permeability of the reagent used.

The sulphydryl populations on the erythrocyte membrane are found to increase as a direct consequence of the nutritional status of the cell. In this study two extremes are shown-namely, a fully glucose activated and a fully deactivated membrane surface (fig 2). Major changes will occur in the hexose transport protein, ${ }^{15}$ and it is interesting to note that by using an average value for the number of copies of this protein found on the membrane, between $1.3 \times 10^{5}$ and $3.0 \times 10^{5}, 25-27$ the difference found is about two sulphydryl functions per protein, a value which, within experimental error, is consistent with previous studies. $^{21-24}$

Figure 2 also shows the sulphydryl population on the membranes of deactivated cells from a group of patients with rheumatoid arthritis. The data indicate that the sulphydryl populations on these cells are lower than found for erythrocytes from healthy volunteers. There are two possible reasons for this result. The concentration of proteins in the membrane might be reduced owing to a small cell surface area or poor protein incorporation due to rapid cell turnover. ${ }^{28}$ The most likely explanation, however, is that oxidative damage has chemically changed the thiol groups into disulphides, sulphinic, or sulphonic acids (in the absence of a bridging group to form a disulphide). After incubation with glucose only a small change in the free sulphydryl groups associTable 2 Number of sulphydryl groups present in the three
distinct domains of the erythrocyte membrane 17 assayed by radiolabelling techniques

\begin{tabular}{|c|c|c|}
\hline Region & No of thiols & $\%$ \\
\hline $\begin{array}{l}\text { Exofacial } \\
\text { Endofacial } \\
\text { Interior }\end{array}$ & $\begin{array}{r}0.99 \times 10^{6} \\
16.7 \times 10^{6} \\
12.3 \times 10^{6} \\
30.0 \times 10^{6}\end{array}$ & $\begin{array}{r}3 \\
56 \\
41\end{array}$ \\
\hline
\end{tabular}

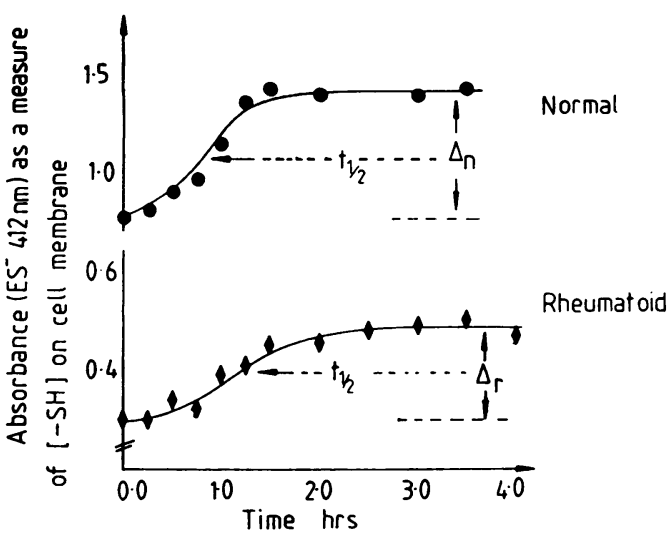

Figure 3 Change in sulphydryl group concentration on the membranes of depleted erythrocytes from 10 healthy normal membranes of depleted erythrocytes from 10 healthy normal with rhewmatoid arthritis ( $(\mathbf{)}$ on activation with glucose.

ated with the proteins has occurred (fig 2). If it is assumed that the number of protein copies remains the same the data suggest that either the two sulphydryl groups necessary for glucose binding are now missing or that they are unavailable owing to impaired protein mobility. In either event protein function is impaired.

The difference in reactivity between normal and rheumatoid erythrocytes can be gauged by the kinetics of their response to glucose. Erythrocytes which had been depleted of glucose were incubated in a $5 \mathrm{mM}$ glucose solution and the change in the thiol population with time was followed by Ellman's reagent. Figure 3 shows a typical response of depleted, deactivated erythrocytes from normal healthy volunteers on binding glucose and so exposing the hindered thiol groups on the exofacial surface. The $t_{1 / 2}$ value reflects the rate of conformational change in the hexose transport protein during sugar binding and for erythrocytes from normal healthy volunteers this occurs at 0.86 (SEM 0.08) hours (fig 3).

With erythrocytes from patients with rheumatoid arthritis the overall change is smaller and, in addition, the activity of those thiols capable of functioning is impaired. Here the $t_{1 / 2}$ occurs at 1.35 $(0 \cdot 2)$ hours. Statistical analysis by the MannWhitney $U$ test indicated a significant $(p<0.05)$ difference between the two groups. Thus both the sulphydryl group population on membrane and their reactivity to glucose are impaired in rheumatoid arthritis.

\section{Conclusions}

The erythrocyte is a cell which is often regarded as being too distant from the disease process to be of any major significance. In comparative studies between the diseased and the healthy state this passive cell is in many ways the cell of choice as a marker of in vitro activity, in that it has only a limited ability for repair and can effectively reflect such changes as membrane damage. In arthritis both the erythrocyte and plasma proteins circulate through areas close to the inflammatory sites. They are also in contact with polymorphs, whose function is altered in the diseased state and which are believed to leak superoxide ions and other radicals. Thus in the diseased state both the plasma proteins and the exofacial surface of the circulating cells come in contact with free radicals to a greater extent than normal. These radicals can react with plasma thiol and exofacial thiol as well 
as lipid. The thiols would form sulphinic or more likely sulphonic acids. Furthermore, Kitigawa has recently shown that hydrogen peroxide induces glucose transport protein activity. ${ }^{29}$ If it is assumed that this chemical process has some similarities to the disease aetiology it would also be expected to manifest itself at the mobile active site of this species and presumably expose the thiols deeper inside the protein structure to the oxidative reactions occurring extracellularly. Thus the downward trend for plasma thiol ${ }^{1-3}$ in the diseased state is mirrored in the membrane thiol and presumably deeper inside the protein also. Thus the damage to the erythrocyte noted here is probably a direct consequence of disease activity. It significance is far greater than that of an artefact of the disease, however, as these reactions impair vital cellular functions in the erythrocyte and may result in stiffer, less functional cells, leading to a shorter half life and greater turnover.

The study reported here on erythrocyte membrane has detected changes associated with one specific functional group on the glucose transport protein. Previously we have reported that this protein might have a dual function-namely, in glucose transport and in the maintenance of a redox link between the inside and the outside of the cell, allowing the reducing environment of the cytosol to control the redox balance of the blood. ${ }^{15}$ We have shown here that this protein has been significantly impaired, and this may result in alteration of both of these processes. Should the electrochemical link between the inside and outside of the cell be interrupted, the reducing environment of the cell will not be able to dissipate the disease induced oxidative stimulus in the plasma at the membrane surface and deeper in the protein channel. This point is reinforced when it is realised that the status of the cytosolic thiol in rheumatoid erythrocytes estimated in whole cells by resonance $\operatorname{Raman}^{30}$ remains in the reduced state rather than the oxidised state.

Two hypotheses can be constructed around these results. It is unlikely that the body produces a large variety of glucose transport proteins and it is a plausible assumption that the one present in the red cell will be the same, or only slightly modified in tertiary structure, as those implanted in the other important cells, such as the $B$ and $T$ lymphocytes, macrophages, and cells from the synovial lining. Thus any damage caused by the disease aetiology to the redox balance and nutritional status of the red cell would be expected to have a parallel in these cells.

1 Munthe E, Jellum E, Aaseth J. Some aspects of the mechanism of action of penicillamine in rheumatoid arthritis. Scand $\mathcal{Y}$ Rheumatol [Suppl] 1979; 28: 6-12.

2 Brown D H, Smith W E. The chemistry of the gold drugs used in the treatment of rheumatoid arthritis. Fournal of the Chemical Society Quarterly Reviews 1980; 9: 217-40. (And references therein.)

3 Banford J C, Brown D H, Hazelton R A, McNeil C J, Sturrock R D, Smith W E. Altered thiol status in patients with rheumatoid arthritis. Rheumatol Int 1982; 2: 107-11.

4 Rae K, McKay C N N, Brown D H, Smith W E, Lewis D Capell H A. Early and late changes in sulphydryl group and copper protein concentrations and activities during drug treatment with aurothiomalate and auranofin. Ann Rheum Dis 1986; 45: 839-46.

5 Egila J. Development and evaluation of procedures for the control of matrix interferences in the ETA-AAS analysis of clinical samples. Strathclyde University, 1988. (PhD thesis.)

6 Lewis D, Capell H A, Smith W E. Cigarette smoking and gold distribution in patients with rheumatoid arthritis. f Rheumatol 1984; 11: 111-3.

7 Rabenstein D L, Arnold A P, Guy R D. 'H-NMR study of the removal of methylmercury from intact erythrocytes by

8 McKay C N N, Brown D H, Reglinski J, Smith W E, Capell $H$ A, Sturrock R D. Changes in glutathione in intact erythrocytes during incubation with penicillamine as detected by ' $\mathrm{H}$ spin echo NMR spectroscopy. Biochim Biophys Acta 1986; 888: 30-5.

9 Riddles P W, Blakeley R L, Zerner B. Ellmans reagent: 5,5'dithiobis(2-nitrobenzoic acid)-a reexamination. Anal Biochem 1979; 94: 75-81.

10 Gerber D A, Cohen N, Guistra R. The ability of non-steroidal anti-inflammatory compounds to accelerate a disulphide interchange reaction of serum sulphydryl groups and $5,5^{\prime}$. dithiobis-(2-nitrobenzoic acid). Biochem Pharmacol 1967; 16: $115-23$.

11 Hall N D, Gillian A H. Effects of antirheumatic drugs on protein SH reactivity of human serum. F Pharm Pharmacol 1979; 31: 676-80.

12 Grimaldi $M$ G. Serum sulphydryl concentration and antirheumatic drugs in rheumatoid patients. $\mathcal{f}$ Pharm Pharmacol 1980; 32: 876.

13 Ellman G L. Tissue sulphydryl groups. Arch Biochem Biophys 1959; 82: 70-7.

14 Famaey J-P, Whitehouse $M W$. Interaction between nonsteroidal anti-inflammatory drugs and biological membranes. Biochem Pharmacol 1975; 24: 1609-15.

15 Reglinski J, Hoey S, Smith W E, Sturrock R D. Cellular response to oxidative stress at sulphydryl group receptor response to oxidative stress at sulphydryl group receptor sites on the $12360-6$.

16 Haest C W M, Plasa G, Kamp D, Deuticke B. Spectrin as a stabilizer of the phospholipid asymmetry in the human erythrocyte membrane. Biochim Biophys Acta 1978; 509: 21-3.

17 Abbott R E, Schachter D. Impermeant maleimides: orientated probes of erythrocyte membrane proteins. $\mathcal{f} \mathrm{Biol}$ Chem 1976; 251: 7176-83.

18 Haest C W M, Kamp D, Deuticke B. Topology of membrane sulphydryl groups in the human erythrocyte: demonstration sulphydryl groups in the human erythrocyte: demonstration of a nonreactive population in in

19 Haest C W M, Kamp D, Plasa G, Deuticke B. Intra- and inter-molecular crosslinking of membrane proteins in intact erythrocytes and ghosts by SH- oxidising agents. Biochim Biophys Acta 1977; 469: 226-30.

20 Ridgwell K, Roberts S J, Tanner M J A, Anstee D J. Absence of two membrane proteins containing extracellular thiol groups in $\mathrm{Rh}_{\text {null }}$ human erythrocytes. Biochem $\mathcal{F}$ 1985; 312: 267-9.

21 Abbott R E, Schachter D, Batt E R, Flamm M. Sulphydryl substituents of the human erythrocyte hexose transport protein. Am f Physiol 1986; 250: C853-60.

22 Batt E R, Abbott R E, Schachter D. Impermeant maleimides: identification of an exofacial component of the human identification of an exofacial component of the human erythrocyte hexose

23 Jung $C$ Y. Inactivation of glucose carriers in human erythrocyte membranes by 1-fluoro-2,4-dinitrobenzene. $\mathcal{F}$ Biol Chem 1974; 249: 3568-73.

24 Pinkofsky H B, Jung C Y. Accessibility of sulphydryl residues induced by cytochalasin $B$ binding and conformational dynamics in the human erythrocyte glucose transporter. Arch Biochem Biophys 1985; 240: 94-101.

25 May J M. Reaction of an exofacial sulphydryl group on the erythrocyte hexose carrier with an impermeant maleimide. f Biol Chem 1988; 263: 13635-40.

26 Lin S, Spudich J A. Biochemical studies on the mode of action of cytochalasin B. 7 Biol Chem 1974; 249: 5778-83.

27 Holman G A, Parker B A, Midgley P J W. Exofacial photoaffinity labelling of the human erythrocyte sugar transporter. Biochim Biophys Acta 1986; 855: 115-26.

28 Dinant H J, de Maat C E M. Erythropoiesis and mean red cell life span in normal subjects and in patients with the anaemia of active rheumatoid arthritis. $\mathrm{Br} \mathcal{F}$ Haematol 1978; 39: 437-44.

29 Kitagawa K, Nishino H, Ogiso Y, Iwashima A. Mechanism of $\mathrm{O}_{2}^{-}$and $\mathrm{H}_{2} \mathrm{O}_{2}$ induced stimulation of sugar transport in mouse fibroblasts BALB/3T3 cells. Biochim Biophys Acta 1988; 972: 293-8.

30 Banford J C, Brown D H, McConnell A A, et al. Determination of thiol concentration in haemolysate by resonance Raman spectrometry. Analyst 1982; 107: 195-9. 